\title{
Entrevista com a Profa. Laura Ancona Lopez Freire
}

\author{
Interview with Prof. Laura Ancona Lopez Freire
}

\author{
Rafael Reimann Baptista1', Thais Russomano² \\ 1 Faculdade de Educação Física e Ciências do Desporto, PUCRS. Centro de Microgravidade da PUCRS, Porto Alegre, RS, Brasil. < rafael.baptista@pucrs.br>. \\ 2 Centro de Microgravidade da PUCRS, Porto Alegre, RS, Brasil. <trussomano@hotmail.com>.
}

\section{Laura Ancona Lopez Freire \\ É Professora na Universidade Paulista (UNIP) e \\ Coordenadora das Relações Internacionais da UNIP.}

Profa. Laura Ancona Lopez Freire, antes de mais nada muito obrigado pela sua atenção. A senhora poderia falar um pouco sobre a sua trajetória acadêmica?

Sou artista plástica, mestre em comunicação e doutoranda em artes visuais. Ainda na graduação iniciei atividade como monitora na Pinacoteca do Estado, a convite de um colega de classe. O trabalho de monitoria em exposições de arte requer preparo e estudo intenso sobre os temas das exposições, consequentemente, esta atividade, além da graduação, me preparou para a docência. Após o ingresso na universidade, a imersão nos conteúdos ensinados em sala de aula e nas pesquisas propostas pelos professores, somados ao aprofundamento das relações de colaboração com os professores e colegas de classe, proporcionaram espaço fértil para o pensamento autônomo. Depois da graduação, ingressei na docência, ministrando aulas sobre criatividade e inovação. Fui para a Itália e me especializei em Criatividade e Ciências Organizacionais com o Prof. Domenico De Masi. Este momento intenso e positivo da minha vida possibilitou o fortalecimento do meu currículo acadêmico e mobilizou em mim uma vontade: oferecer a mesma oportunidade de internacionalização para os jovens brasileiros. Tive oportunidade de criar o departamento de Relações Internacionais da Universidade Paulista, onde atuo como diretora, e fui indicada para a coordenação institucional desta universidade para o Programa Ciências sem Fronteiras.

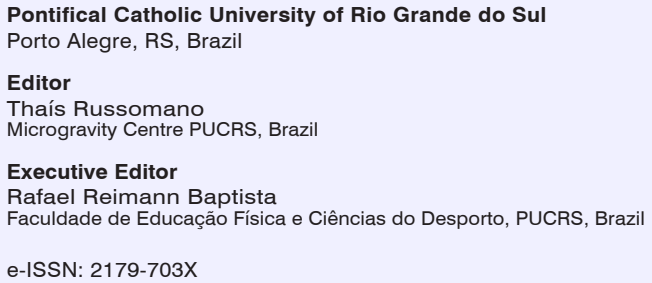

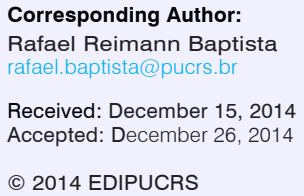

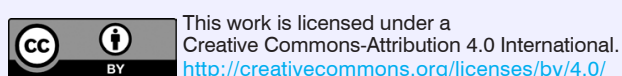


- A senhora ocupa hoje um cargo relacionado com internacionalização. O que é internacionalização da educação superior para a senhora e quais as tendências que a senhora percebe para a internacionalização do ensino superior?

A vontade de oferecer a mesma oportunidade para os jovens brasileiros veio ao encontro de uma tendência global. Isso permitiu a criação do escritório de Relações Internacionais da UNIP, possibilitando o fortalecimento da internacionalização para a graduação, pós-graduação, mestrado, doutorado e pós-doutorado. Houve um aumento dos números de parceira e, o mais importante, de ações internacionais conjuntas.

A internacionalização da educação permite a troca de conhecimento e colaboração em pesquisa entre acadêmicos de todo mundo. O mais importante da internacionalização da educação superior é que se criam fortes laços intelectuais e também de amizade. Esses laços já existiam entre os sujeitos antes da globalização, porém, eles aconteciam com mais dificuldade e restritos apenas a algumas comunidades. Hoje com a facilidade de comunicação, cria-se uma comunidade intelectual global menos isolada, mais aberta e cooperativa. Neste sentido, o desenvolvimento da ciência é extremamente fortalecido. Estamos numa era em que podemos aproveitar toda a capacidade intelectual humana de criação e de inovação. O trabalho conjunto, em tempo rápido, multicultural e multidisciplinar criam esta força e este poder extremo de desenvolvimento. Hoje não existe a criação isolada, as realizações ocorrem em conjunto. Atribuir um prêmio a uma só pessoa ou país fazia sentido no passado, mas hoje sabemos que as grandes descobertas e realizações contam com as mentes mais brilhantes de todo o mundo. Muitas vezes elas estão trabalhando de forma isolada, mas estão conectadas por pensamentos e informações que são veiculados pelas mídias. Ou seja, estão pensando em conjunto, mesmo que não se deem conta disto. Outras vezes esta colaboração é direta e consciente.

Você perguntou sobre a tendência para a internacionalização do ensino superior. Eu acredito que este é um caminho sem volta, que não haverá mais isolamento intelectual e que a internacionalização que foi $\mathrm{em}$ outras épocas tratadas coisa rara, vai se tornar bastante corriqueira. A tendência é a de que mais cursos serão oferecidos em outras línguas, o que facilitará ainda mais a troca de conhecimento e de pessoal.

Por esse motivo, esta é uma era de grande potencial criativo-inovador.

A sua colaboração com a nossa Universidade começou por meio da ideia de interrelacionar artes plásticas com ciências espaciais. De onde surgiu esta inspiração?

Eu estava pesquisando e analisando obras de arte visual que apresentavam imagem e texto. Algumas delas faziam referência ao espaço aéreo. A obra Anywhere is my Land de Antonio Dias faz referência ao espaço das galáxias. Vemos um quadro preto com vários pontos brancos distribuídos de forma que lembram uma galáxia, sobre essa imagem vemos uma grade branca como a imagem de uma tabela sobre uma imagem numa tela de controle aéreo. Parece que estamos olhando para uma galáxia de dentro de uma espaçonave ou num escritório de controle aéreo espacial. Vemos ainda no canto superior direito da imagem a inscrição Anywhere is my Land.

Esta obra me tocou profundamente, pois ela remete o observador a uma idéia poderosa: o ser humano pode habitar outros planetas. Para mim, olhar a obra Anywhere is my Land é como olhar um quadro de uma marinha numa época onde os continentes ainda eram desconhecidos. As pessoas deviam olhar para o mar e para as paisagens marítimas e pensar - "o que há do outro lado?". É isto que eu penso diante da obra de Antônio Dias. Essa imagem me remete ao mistério do universo e da própria capacidade humana de expansão. Onde podemos chegar?

O Prof. Dr. Ernesto Boccara enfatiza em suas aulas no Instituto de Arte da UNICAMP o papel dos artistas que captam os sonhos individuais e coletivos e os expressam através da arte. A arte acompanha e revela o inconsciente humano desde os tempos primitivos até a atualidade.

A idéia da interrelação de artes plásticas com o espaço aéreo tomou forma quando encontrei o Prof. Rafael em Shanghai. Nós fomos convidados a ministrar aula na Universidade Jiao Tong, ele sobre o tema do espaço aéreo e eu sobre o tema da arte. O Prof. Rafael em sua aula pediu para que imaginássemos como seria a vida em Marte e eu comecei a imaginar a arte neste contexto.

Quais são as possibilidades que a senhora enxerga de interrelação entre as artes plásticas e o espaço?

Esta interrelação já existe. Encontramos inúmeras representações de astros, estrelas e cometas. Basta ver algumas imagens da alquimia (citar). As figuras de seres alados, por exemplo, podem ser expressão do sonho humano de voar.

Mais recentemente encontramos artistas plásticos trabalham sobre a temática do espaço aéreo. Andy Warhol, por exemplo, na obra Main Moonwalk, apresenta a imagem do homem na lua traduzida para a linguagem da Pop Art. A artista Liliane Ljin, criou uma série de obras exclusivamente dedicada ao espaço aéreo. 
Existe uma possibilidade concreta dos seres humanos colonizarem o Planeta Marte a partir das próximas décadas. Qual(ais) será(ão) o(s) papel(eis) da arte neste processo?

A maior relação existente entre as artes e o espaço aéreo se refere as artes aplicadas. Estamos falando do design, que procura unir beleza e funcionalidade para aeronaves, objetos e roupas espaciais. Há um instinto natural do ser humano que o leva a procurar fazer as coisas da maneira mais prática e bonita possivel.

Podemos pensar em outras formas de interrelacionar as artes com espaço aéreo imaginando e experimentando a realização de obras no espaço. Este é o tema da minha tese de doutorado na Unicamp intitulada "Arte no espaço aéreo: experiências na microgravidade".

É importante notar que a arte faz parte da história humana desde seus primórdios. A arte no espaço provavelmente acontecerá de forma tão natural quanto aconteceu no nosso planeta.

A senhora conhece algum outro projeto relacionado a artes e ciências espaciais? Quais são as suas impressões sobre eles?
Há vários projetos, entre eles, quero destacar o Nasa Artspace, que foi projetado para aumentar a consciência e participação pública através do poder da arte, inspirando e convidando o público a participar da convergência entre arte, ciência e tecnologia. Há também grupos como o Canadian Aerospace Artists Association. Mas acho importante destacar que longe destes grupos especializados, há vários artistas contemporâneos que tocam, em algum momento, no tema do universo das galáxias de forma menos direta e mais conceitual.

Fale um pouco sobre o projeto que pretende realizar sobre artes plásticas e o espaço.

A pesquisa parte da procura dos primeiros indícios de um pensamento visual voltado para o espaço aéreo (Acredito que estes pensamentos são ação inicial e motivação para uma serie de desdobramentos que vão culminar, no futuro, na aventura da vida do ser humano no espaço) para chegar até os dias de hoje, sempre a partir de registros artísticos visuais. Para finalizar a pesquisa, pretendo analisar simulações de criação artística no espaço de microgravidade em simuladores do Laboratório MicroG da PUCRS, para saber como corpo e material respondem ao novo espaço. 
Parceiros:

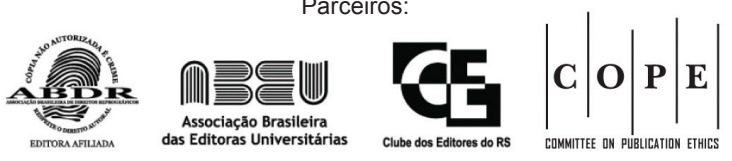

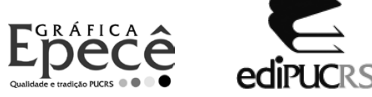

